\title{
BMJ Open Trends in hospital admissions and surgical procedures for degenerative lumbar spine disease in England: a 15 -year time-series study
}

\author{
Vinothan Sivasubramaniam, ${ }^{1}$ Hitesh C Patel, ${ }^{2}$ Baris A Ozdemir, ${ }^{3,4}$ \\ Marios C Papadopoulos ${ }^{1}$
}

To cite: Sivasubramaniam V, Patel HC, Ozdemir BA, et al. Trends in hospital admissions and surgical procedures for degenerative lumbar spine disease in England: a 15-year timeseries study. BMJ Open 2015:5:e009011. doi:10.1136/bmjopen-2015009011

- Prepublication history and additional material is available. To view please visit the journal (http://dx.doi.org/ 10.1136/bmjopen-2015009011).

Received 8 June 2015 Revised 9 November 2015 Accepted 10 November 2015

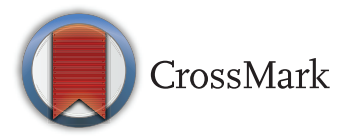

\footnotetext{
${ }^{1}$ Department of Neurosurgery, St George's Hospital, London, UK ${ }^{2}$ Department of Cardiology, The Royal Brompton \& Harefield NHS Foundation Trust, London, UK ${ }^{3}$ Department of Vascular Surgery, St George's Hospital, London, UK ${ }^{4}$ London Deanery Surgical Rotation, UK
}

Correspondence to Vinothan Sivasubramaniam; vino.siva@nhs.net

\section{ABSTRACT}

Objectives: Low back pain (LBP), from degenerative lumbar spine disease, represents a significant burden on healthcare resources. Studies worldwide report trends attributable to their country's specific demographics and healthcare system. Considering England's specific medico-socioeconomic conditions, we investigate recent trends in hospital admissions and procedures for LBP, and discuss the implications for the allocation of healthcare resources.

Design: Retrospective cohort study using Hospital Episode Statistics data relating to degenerative lumbar spine disease in England, between 1999 and 2013. Regression models were used to analyse trends.

Outcome measures: Trends in the number of admissions and procedures for LBP, mean patient age, gender and length of stay.

Results: Hospital admissions and procedures have increased significantly over the study period, from 127.09 to 216.16 and from 24.5 to 48.83 per 100000 , respectively, $(p<0.001)$. The increase was most marked in the oldest age groups with a 1.9 and 2.33-fold increase in admissions for patients aged 60-74 and $\geq 75$ years, respectively, and a 2.8 -fold increase in procedures for those aged $\geq 60$ years. Trends in hospital admissions were characterised by a widening gender gap, increasing mean patient age, and decreasing mean hospital stay $(p<0.001)$. Trends in procedures were characterised by a narrowing gender gap, increasing mean patient age $(p=0.014)$ and decreasing mean hospital stay $(p<0.001)$. Linear regression models estimate that each hospital admission translates to 0.27 procedures, per 100000 $(95 \% \mathrm{Cl} 0.25$ to $0.30, r$ 0.99, $p<0.001 ; r$, Pearson's correlation coefficient). Hospital admissions are increasing at 3.5 times the rate of surgical procedures (regression gradient 7.63 vs 2.18 per 100 000/year).

Conclusions: LBP represents a significant and increasing workload for hospitals in England. These trends demonstrate an increasing demand for specialists involved in the surgical and non-surgical management of this disease, and highlight the need for services capable of dealing with the increased comorbidity burden associated with an ageing patient group.

\section{Strengths and limitations of this study}

- The use of routinely collected national administrative data allowed for the analysis of trends in admissions and surgical procedures for low back pain (LBP) throughout England, for a prolonged time period.

- As Hospital Episode Statistics is collected independently of this study, it is not subject to studyrelated bias or affected by factors that may have influenced hospital trends in LBP.

- This study provides important England-specific population-level data about longitudinal trends, associations and patterns of care for LBP.

- Limitations inherent to using aggregate administrative data include coding errors relating to inaccurate representation of admissions and procedures, data duplication and interhospital variability.

\section{INTRODUCTION}

Low back pain (LBP), from degenerative lumbar spine disease, is one of the most prevalent non-fatal conditions worldwide, and a significant cause of long-term disability. ${ }^{1}{ }^{2}$ In England, it is one of the leading causes of physician attendances, hospitalisation and utilisation of social care services. ${ }^{3}$ It confers a significant economic burden in terms of funding of health resources, disability benefits and effect on industry from sick leave. ${ }^{3}$

Several studies in other countries, using national and medical insurance databases, have identified interesting trends in hospitalisation for degenerative lumbar spine disease. These trends have been attributed to the country's specific healthcare system, demographics, medical technological advances, and profitability of treatment modalities. ${ }^{4-9}$ There is sparse data on trends in hospitalisation for this disease in England. 
The aim of this study is to investigate the longitudinal trends in hospital admissions and surgical procedures for degenerative lumbar spine disease in England, between 1999 and 2013. Considering England's specific medico-socioeconomic conditions, which include the existence of a health service free at the point of delivery, we evaluate whether it follows trends seen in other countries, and discuss the implications for allocation of healthcare resources.

\section{METHODS}

Annual aggregate data for all hospital admissions and procedures in England, from 1999 to 2013, were retrieved from Hospital Episode Statistics (HES), available from the Health and Social Care Information Centre.

In this study, the term LBP refers to degenerative disease resulting in LBP with or without radicular or neurogenic claudicant symptoms. This encompasses a variety of underlying processes including herniated disc disease, isthmic/degenerative spondylolisthesis, spinal stenosis and non-specific LBP (back pain not attributable to spinal instability or associated with radicular symptoms). Surgical procedures refer to surgery for degenerative lumbar spine disease, and do not include surgery for non-degenerative pathology such as trauma or malignancy.

The HES data set groups primary diagnoses according to the World Health Organization's 10th revision of the International Classification of Diseases. The codes relevant to our study were M54.1, M54.3, M54.4 and M54.5, referring to admissions with the primary diagnosis of radiculopathy, sciatica, lumbago with sciatica and LBP, respectively. Finished consultant episodes, representative of hospital admissions, were analysed with respect to gender and four different age groups $(0-15,16-59,60-$ 74 and $\geq 75$ years).

Primary procedures, defined as the most resource intensive procedure performed during the hospital episode, were identified using to the fourth version of the Office of Population Censuses and Surveys Classification of Interventions and Procedures. Codes representing surgical procedures relevant to degenerative lumbar spine disease (see online supplementary appendix) were aggregated and analysed to produce admission trends stratified by age and gender. The data for 1999 were excluded from our analysis of surgical interventions as only the less detailed three-character procedure codes were available, deemed insufficient for this study.

Mid-year estimates of English population denominators grouped by age and gender were obtained from the Office of National Statistics. Annual hospital admissions and surgical interventions are reported per 100000 of the population, and further stratified by broad age groups and gender.

Time trends were investigated using linear regression models with the gradient expressed as $\beta$ values with $95 \%$ confidence intervals, per 100000 of the population. Correlation is represented by Pearson's correlation coefficient $(r)$. Continuous variables were compared using the independent samples t test. A $p$ value of $<0.05$ was chosen to imply statistical significance. Statistical Package for the Social Sciences was used to perform data analysis.

This study is exempt from UK National Ethics Committee approval as it analyses freely available anonymised aggregate data used for administrative purposes.

\section{RESULTS}

Trends in hospital admissions for LBP

Overall hospital admissions

Over the 15-year period from 1999 to 2013, there was a significant rise in the overall hospital admissions for LBP, increasing from 127.09 in 1999 to 216.26 in 2013, per 100000 population (figure 1). This represents a 1.7-fold increase or an annual increase of 7.63/100 000 ( $\beta 7.63$ (CI 6.75 to 8.50$), \mathrm{r}=0.98, \mathrm{p}<0.001$ ).

\section{Gender}

Hospital admissions for men and women increased over the 15-year period ( $\beta 4.97$ (CI 4.33 to 5.61) and 10.22 (CI 9.1 to 11.35 ) respectively, $\mathrm{r}=0.98$ for both, $\mathrm{p}<0.001$ ), with admissions being significantly greater in women than in men $(\mathrm{p}<0.001)$ (figure 2$)$. Hospital admission rates for women increased at approximately twice the rate of men's, resulting in a widening gender gap over the 15-year period $(\mathrm{p}<0.001)$.

\section{Mean age of patients at admission}

Age at admission increased from 52.5 years in 1999 to 56.5 years in 2013, representing an estimated 0.28 year increase in the average patient age per annum, over the 15 years $(\beta 0.28$ (CI 0.21 to 0.34$), r=0.93, p<0.001)$.

\section{Age categories}

The data demonstrates a significant increase in hospital admissions for each of the four age groups over the study period $(p<0.001)$ (figure 3$)$. The greatest increase is seen in those aged $60-74$ and $\geq 75$ years, evident by a 1.9 and 2.33-fold increases, respectively, (from 199.43 to 379.34, and from 209.96 to 488.60 , per 100000 , respectively). Hospital admissions for those aged 0-14 years increased from 3.99 to 6.39 per 100000 , representing a 1.6-fold increase in a paediatric population, and from 140.11 to 200.8 per 100000 for patients aged 1559 years, over the 15 years. The older the age group the greater was the observed annual rate of increase in hospital admissions $(\mathrm{p}<0.001)$ (figure 4$)$.

\section{Mean hospital stay}

The average length of hospital stay decreased from 5.7 days in 1999 to 2.7 days in 2014, representing a $52 \%$ decrease or a fall of 0.25 years per study year $(\beta 0.25$ (CI -0.21 to -0.29$), r=0.96, p<0.001)$. 


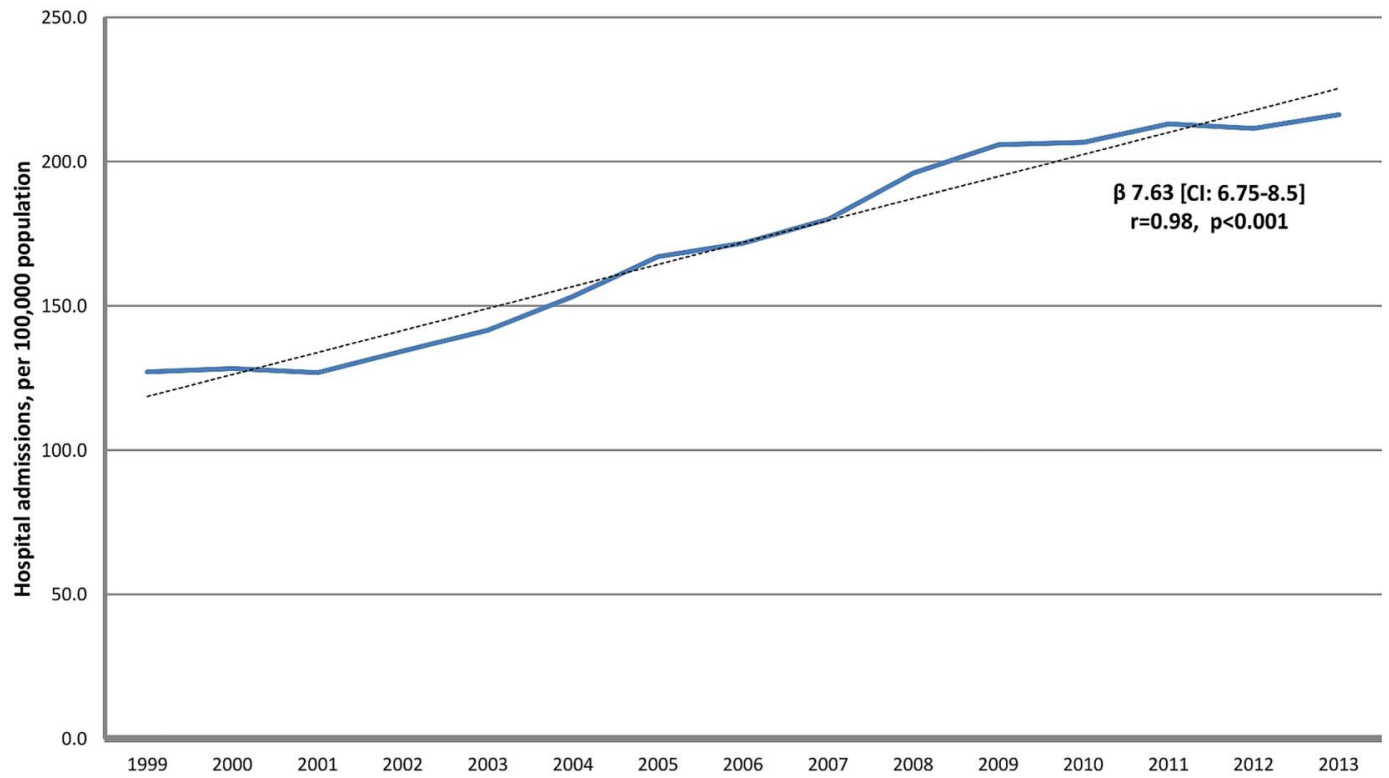

Figure 1 Hospital admissions for low back pain in England, 1999-2013. Solid line-admissions per 100000 population, dashed line-linear regression model.

Trends in surgical procedures for degenerative lumbar spine disease

\section{Overall surgical procedures}

Over the study period, there was a significant increase in the overall number of surgical procedures performed for degenerative lumbar spine disease (figure 5). Recorded procedures almost doubled from 24.5 to 48.83 per 100000 , with an estimated 2.18/100 000 increase each year ( $\beta 2.18$ (CI 1.98 to 2.37 ), $r=0.99, \mathrm{p}<0.001$ ).

Association between hospital admissions and the number of surgical procedures

There was a strong positive linear correlation between hospital admissions and procedures, with every incremental admission translating to an estimated 0.27/
100000 increase in surgical interventions ( $\beta 0.27$ (CI 0.25 to 0.30$), r=0.99, \mathrm{p}<0.001)$.

\section{Gender}

There was a significant increase in surgical procedures for both genders over the study period $(p<0.001)$. There was a statistically significant difference between genders for the early years only $(2000-2003, p=0.01)$, but not for the latter years $(2011-2013, \mathrm{p}=0.73)$, suggesting a narrowing of any early gender gap.

\section{Mean patient age}

This increased from 49.4 in 2000 to 52.3 years in 2013 $(p=0.014)$, with an estimated increase in mean patient

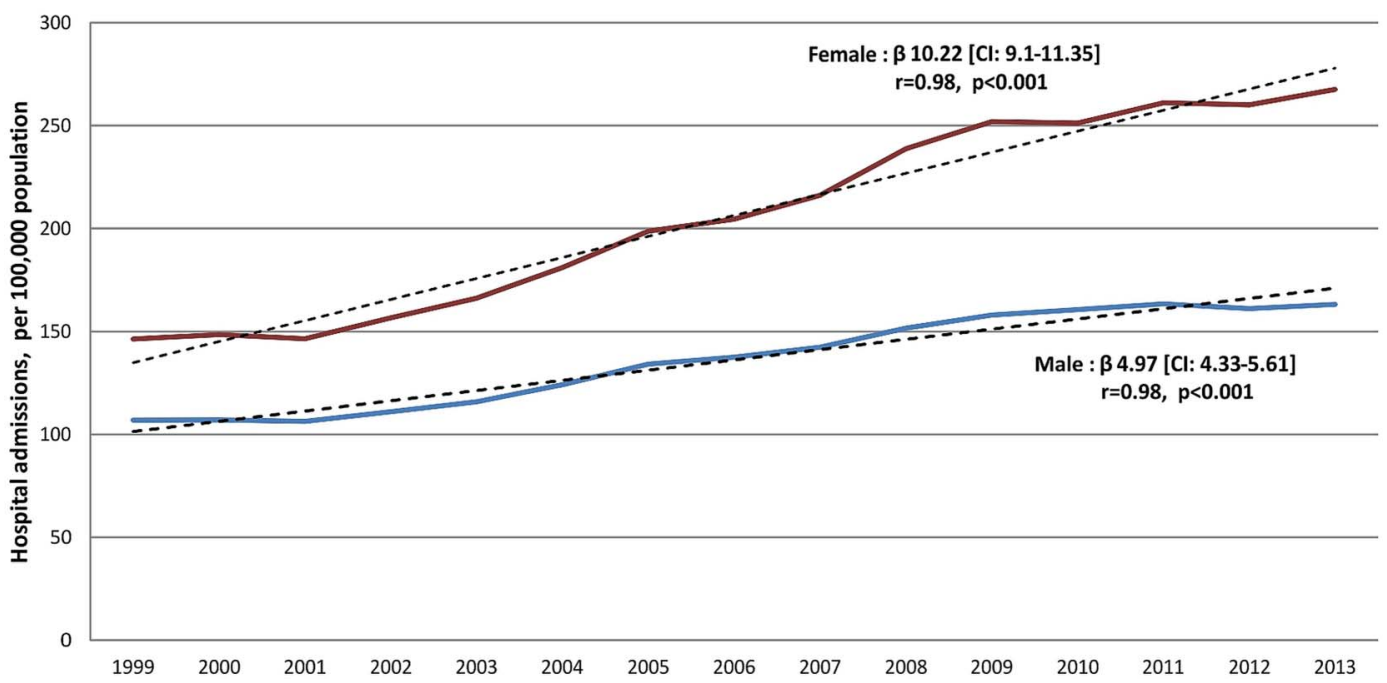

Figure 2 Male and female hospital admissions for low back pain, 1999-2013. Solid lines-admissions per 100000 population, dashed lines-linear regression model. 


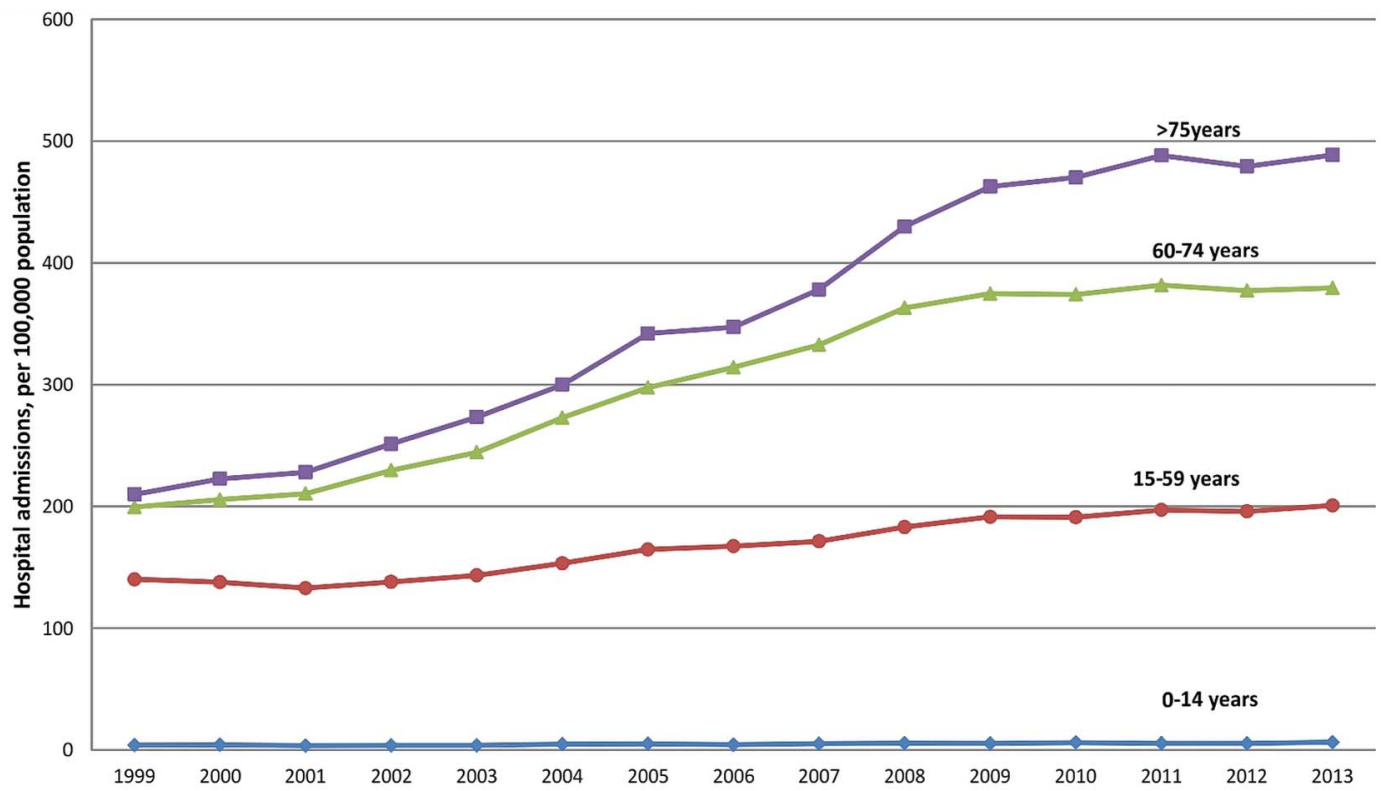

Figure 3 Hospital admissions for low back pain in England by age groups, 1999-2013.

age of 0.2 years per annum, over the study period $(\beta$ 0.20 (CI 0.14 to 0.27 ), $\mathrm{r}=0.8, \mathrm{p}<0.001$ ).

\section{Age categories}

With the exception of patients aged 0-14 years, there was a significant increase in the uptake of surgery for all age groups $(15-59,60-74$ and $\geq 75$ years, $\mathrm{p}<0.001)$ (figure 6). The most significant increases were seen in the oldest age groups, with a 2.8-fold increase in those aged $60-74$ and $\geq 75$ years over the study period (from 32.54 to 89.95 and from 24.89 to 70 , per 100000 , respectively). In contrast, those aged $15-59$ years demonstrated a 1.7 -fold increase (30.21 to 50.22 per 100000 ). There was a fall in the number of surgical procedures recorded for those aged $0-14$ years, from 0.67 in 2000 to 0.29 in 2014 per $100000(\mathrm{p}=0.007)$.

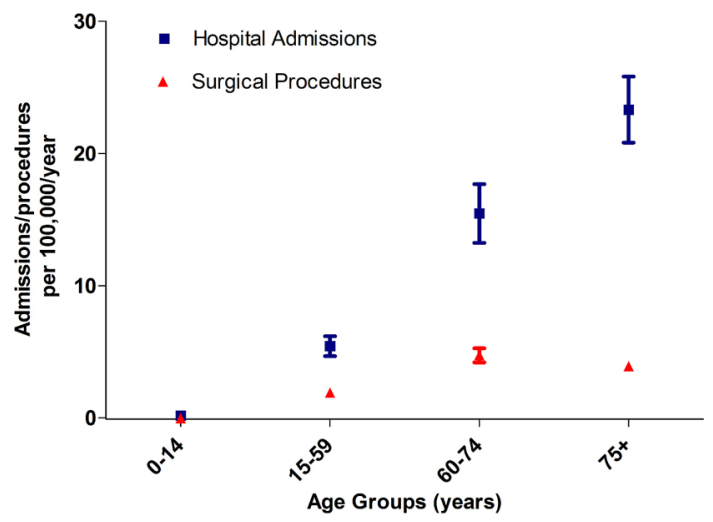

Figure 4 Age specific annual rate of increase in hospital admissions and procedures, 1999-2013. Values correspond to each age group's $\beta$ coefficient with their respective $95 \%$ Cls represented as error bars.
The rate of increase was greatest for patients aged $\geq 60$ years, with patients aged $0-14$ years demonstrating a slowly falling trend $(0-14$ years: $\beta-0.02$ (CI -0.01 to -0.04 ), $r=-0.68 ; 15-59$ years: $\beta 1.9$ (CI 1.65 to 2.15 ), $\mathrm{r}=0.98$; $60-74$ years: $\beta 4.73$ (CI 4.19 to 5.27 ), $\mathrm{r}=0.98 ; \geq 75$ years: $\beta 3.9$ (CI 3.57 to 4.23 ), $\mathrm{r}=0.99 ; \mathrm{p}<0.01$ for all groups) (figure 4 ).

\section{Mean hospital stay}

The mean hospital stay for those undergoing surgery decreased from 8.26 to 3.58 days over the study period, representing a $57 \%$ decrease or a fall of 0.39 days per study year $(\beta-0.39$ ( -0.36 to -0.42$), \mathrm{r}=-0.99, \mathrm{p}<0.001)$.

\section{DISCUSSION}

This study identified significant increases in hospital admissions and procedures for degenerative lumbar spine disease in England, between 1999 and 2013. The findings are, in general, concordant with studies from other countries. ${ }^{4-9}$ The results reveal a widening gender gap, with women accounting for an increasingly greater proportion of hospital admissions. Interestingly, this has not translated to a similar trend in surgical procedures, where any gender gap in the early years is decreasing, in direct contrast to studies from other countries. ${ }^{5}$

This suggests that although more women are admitted for LBP, they appear to be managed non-surgically. It is also possible that the gender gap may be related to gender-specific coding inconsistencies: for example, gynaecological flank pain incorrectly coded as lumbago or LBP. Considering that this data mirrors trends identified in other countries, this is less likely. Further investigation into trends in specific surgical procedures may identify procedure-specific gender gaps not revealed when analysing aggregate surgical procedures. 


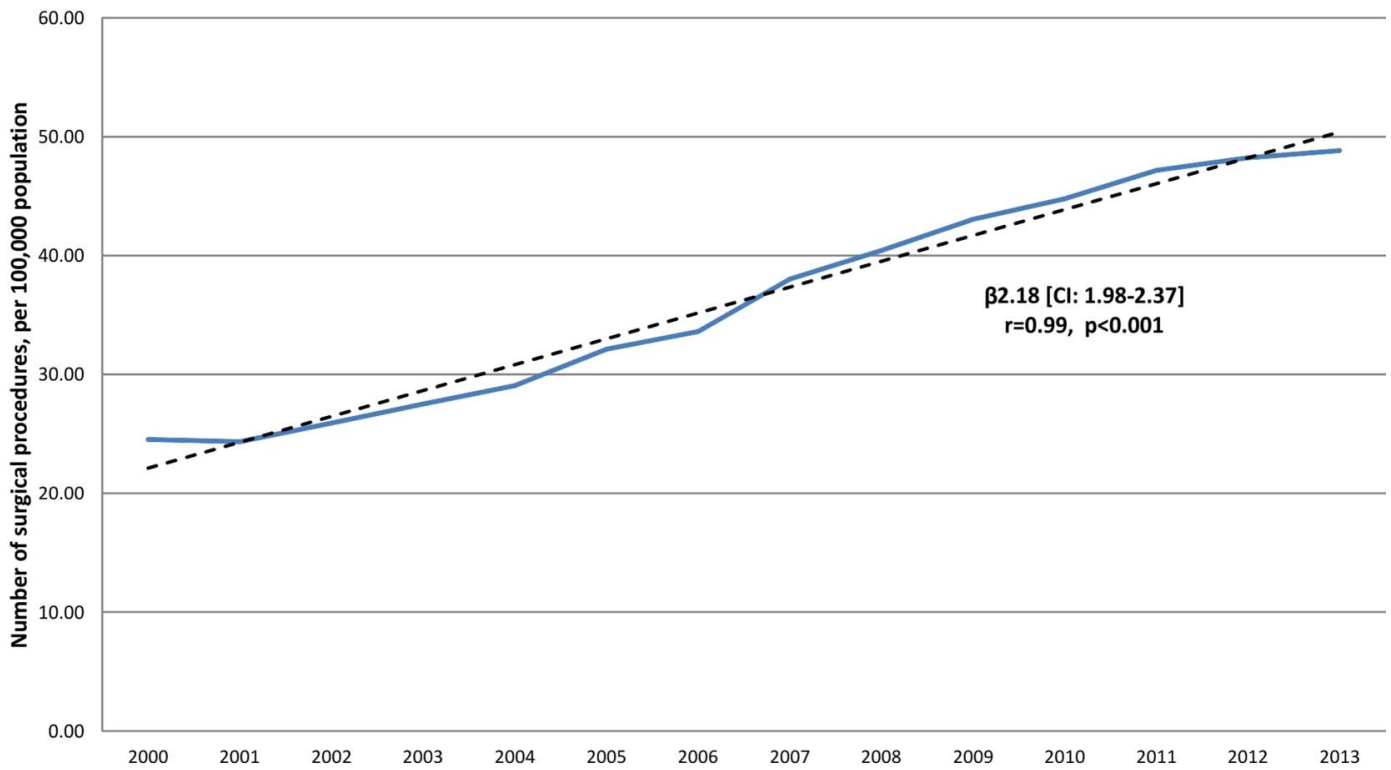

Figure 5 The number of surgical procedures performed for degenerative lumbar spine disease, 2000-2013. Solid line-number of procedures per 100000 population. Dashed line-linear regression model.

As with other surgical trends in England, in the context of an ageing population, there has been a shift in the burden of this disease to the oldest population groups (60-74 and $\geq 75$ years), resulting in an increase in the mean patient age for hospital admissions and surgical interventions. ${ }^{10-12}$ Unexpectedly, over the same period, the average hospital stay has halved. Although the data do not allow us to address the underlying reasons for this, it may be attributable to improved perioperative care (such as high risk anaesthetic clinics optimising patients prior to surgery), and improved postoperative therapy and social care, allowing for earlier patient mobilisation and discharge; or possibly, the result of the recent paradigm shift towards moving care into the community with better community services for chronic conditions.

Our observation of an ageing patient group and falling mean hospital stay is well established in the international literature. ${ }^{5} 913$ There is, however, a well described increase in the burden of comorbidities associated with increased rates of postoperative complications and mortality in older patients. ${ }^{5} 1415$ Further analysis of trends in age-specific mortality and morbidity for lumbar spine surgery in England may better reflect the true burden of this disease on hospital resources, as the significantly shorter stay by younger patients may have skewed the data. An advancing mean patient age has important implications for provision of critical care

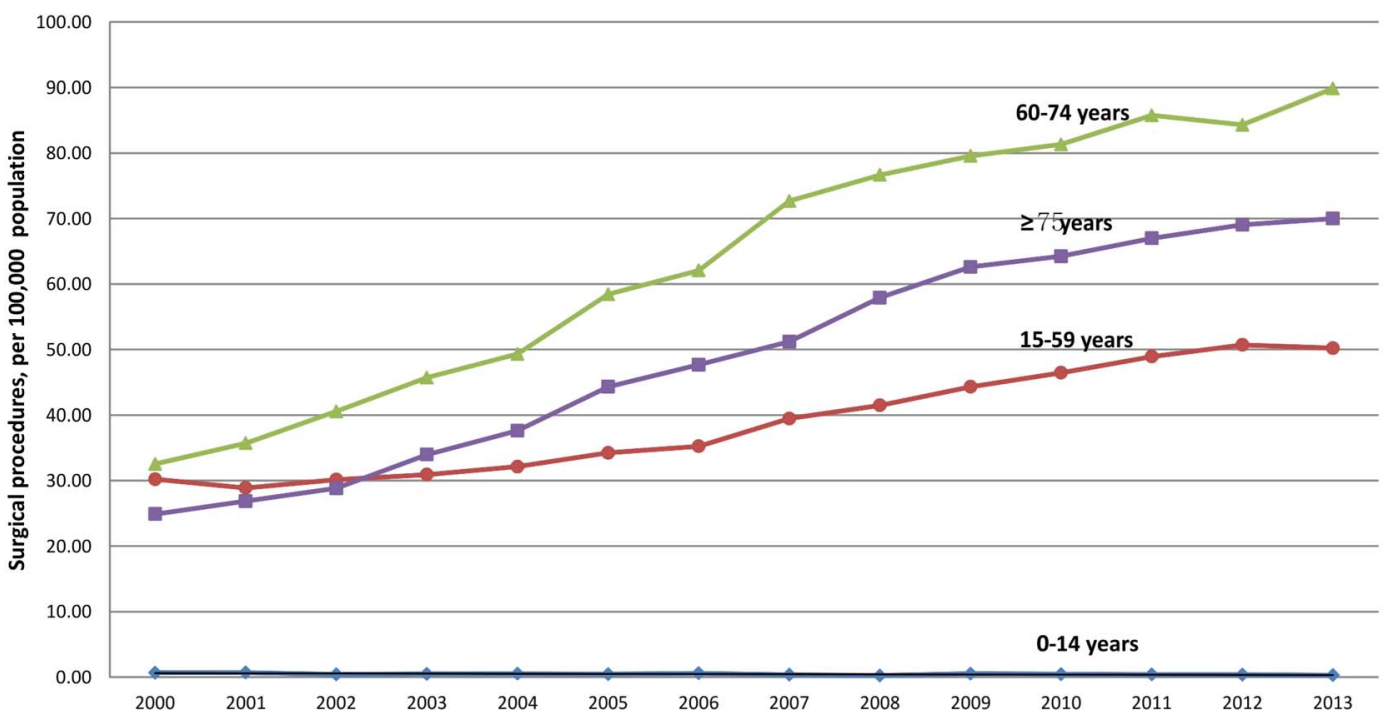

Figure 6 Number of surgical procedures for degenerative lumbar spine disease by age groups, 2000-2013. 
resources, and demand for medical specialties involved in managing the increased comorbidity burden.

The data identify an under-appreciated trend in increasing hospital admissions for patients aged 0-14 years. Although the data cannot identify the underlying reasons, it may be attributable to the rising obesity levels in children. ${ }^{16}$ LBP is less well recognised in this age group, and consequently, health resources are relatively suboptimal. ${ }^{17}$ The data suggest growing demand and indicate the need for provision of paediatric services to manage the underlying causes in an effort to attenuate current trends.

This study estimates that for every 100 patients being admitted with LBP, approximately 27 undergo surgical intervention ( $\beta 0.27$ (CI 0.25 to 0.30 ), $\mathrm{r}=0.99, \mathrm{p}<0.001$ ). Regression models looking at hospital admissions and surgical procedures separately (figures 1 and 5), illustrate that admissions are increasing at 3.5 times the rate of surgical interventions ( $\beta$ values of 7.63 vs 2.18, respectively). This highlights a disproportionate growth in demand for those involved in the non-surgical management of LBP, such as therapists and pain specialists, and indicates that more funding might be needed in the future for these services. A proportion of this difference may be attributable to a lack of surgical capacity to deal with the increasing workload. Further analysis of waiting lists and mean waiting times may elucidate the factors accounting for this observation.

Current guidelines regarding non-surgical management recommend considering structured supervised exercise programmes, manual therapies and acupuncture in patients with non-specific LBP. ${ }^{18}$ The medical literature regarding their effectiveness is complicated by the heterogeneous nature of these treatment modalities and the patient population, with pooled analyses and systematic reviews demonstrating, at best, a modest benefit. ${ }^{19}{ }^{20}$ Considering the trends identified in this study, it would be prudent to increase funding into high level research (with sufficient long-term follow-up) aimed at identifying the relative effectiveness of nonsurgical treatment modalities in different patient groups, so that resources may be optimally allocated to match the increasing future demand for these services, and reduce hospital burden.

Limitations inherent to using aggregate administrative data include coding errors relating to inaccurate representation of admissions and procedures (eg, lumbar fixation for trauma being incorrectly counted in the codes selected for this study), interhospital variability, data duplication, and discrepancy between finished consultant episodes and admissions. Considering the size of the data set and duration of this study, any systematic error is likely to have evened out, especially when investigating trends rather than absolute values. Furthermore, systematic reviews have demonstrated a good correlation between reported and actual validated data, reporting coding accuracies between 83 and 92\%, which is sufficient for use in this study. ${ }^{21}{ }^{22}$ Finally, the trends identified in this study not only reflect those found in other countries, but also mirror patterns seen in other surgical pathologies in England that have been subject to similar changing demographics, surgical innovation and changes in health guidelines. ${ }^{4-6} 8-12$

Although this data do not directly address the underlying reasons for the observed trends, over the past 15 years, there have been numerous factors that may have influenced hospital trends for degenerative lumbar spine disease in England. These include demographic changes such as an ageing population, rise in obesity, sedentary lifestyles, public health factors such as changes in health guidelines, and surgical factors such as advancements in diagnostic imaging and proliferation of spinal instrumentation and implant systems. ${ }^{723}$

\section{CONCLUSION}

LBP, from degenerative lumbar spine disease, represents a significant and increasing workload for hospitals in England. The strong trends and associations identified in this study demonstrate an increasing demand for specialists involved in the surgical and non-surgical management of this condition. It highlights the need for the provision of services capable of dealing with the increased comorbidity burden associated with an ageing patient group. An under-appreciated trend in increasing admissions for patients aged 0-14 years is identified, prompting the need for research into underlying causes, and the provision of appropriate paediatric services to attenuate this adverse finding.

Contributors VS conceived and designed the study, analysed and interpreted the data, drafted the article, made appropriate revisions and approved the final version of the manuscript. HCP provided statistical analysis, and critically reviewed and revised the original draft, and approved the final version. BAO assisted in the interpretation of the data, critically reviewed and revised the manuscript, and approved the final version. MCP is the guarantor and assisted in the conception of the study, critically reviewed the manuscript, and approved the final version. All authors agree to be accountable for the study.

Funding This research received no specific grant from any funding agency in the public, commercial or not-for-profit sectors.

Competing interests None declared.

Ethics approval This study is exempt from UK National Ethics Committee approval as it analyses freely available anonymised aggregate data used for administrative purposes.

Provenance and peer review Not commissioned; externally peer reviewed.

Data sharing statement No additional data are available.

Open Access This is an Open Access article distributed in accordance with the Creative Commons Attribution Non Commercial (CC BY-NC 4.0) license, which permits others to distribute, remix, adapt, build upon this work noncommercially, and license their derivative works on different terms, provided the original work is properly cited and the use is non-commercial. See: http:// creativecommons.org/licenses/by-nc/4.0/

\section{REFERENCES}

1. Hoy D, March L, Brooks $P$, et al. The global burden of low back pain estimates from the Global Burden of Disease 2010 study. Ann Rheum Dis 2014;73:968-74.

2. Vos T, Flaxman AD, Naghavi M, et al. Years lived with disability (YLDs) for 1160 sequelae of 289 diseases and injuries 1990-2010: 
a systematic analysis for the Global Burden of Disease Study 2010. Lancet 2012;380:2163-96.

3. Maniadakis N, Gray A. The economic burden of back pain in the UK. Pain 2000;84:95-103.

4. Deyo RA, Mirza SK. Trends and variations in the use of spine surgery. Clin Orthop Relat Res 2006;443:139-46.

5. Pumberger M, Chiu YL, Ma Y, et al. National in-hospital morbidity and mortality trends after lumbar fusion surgery between 1998 and 2008. J Bone Joint Surg Br 2012;94:359-64.

6. Rajaee SS, Bae HW, Kanim LE, et al. Spinal fusion in the United States: analysis of trends from 1998 to 2008. Spine 2012;37:67-76.

7. Kim $\mathrm{P}$, Kurokawa R, Itoki K. Technical advancements and utilization of spine surgery -international disparities in trend-dynamics between Japan, Korea, and the USA. Neurol Med Chir (Tokyo) 2010;50:853-8

8. Weinstein JN, Lurie JD, Olson PR, et al. United States' trends and regional variations in lumbar spine surgery: 1992-2003. Spine 2006;31:2707-14

9. Yoshihara $\mathrm{H}$, Yoneoka D. National trends in the surgical treatment for lumbar degenerative disc disease: United States, 2000 to 2009 Spine J 2015;15:265-71.

10. Evans LM, Owens D, Scott-Coombes DM, et al. A decade of change in the uptake of parathyroidectomy in England and Wales. Ann $R$ Coll Surg Engl 2014;96:339-42.

11. von Allmen RS, Anjum A, Powell JT. Incidence of descending aortic pathology and evaluation of the impact of thoracic endovascular aortic repair: a population-based study in England and Wales from 1999 to 2010. Eur J Vasc Endovasc Surg 2013;45:154-9.

12. von Allmen RS, Anjum A, Powell JT, et al. Hospital trends of admissions and procedures for acute leg ischaemia in England, 2000-2011. Ann R Coll Surg Engl 2015;97:59-62.

13. Peul WC, Bredenoord AL, Jacobs WC. Avoid surgery as first line treatment for non-specific low back pain. BMJ 2014;349:g4214.
14. Ma Y, Passias P, Gaber-Baylis LK, et al. Comparative in-hospital morbidity and mortality after revision versus primary thoracic and lumbar spine fusion. Spine $J$ 2010;10:881-9.

15. Shen Y, Silverstein JC, Roth S. In-hospital complications and mortality after elective spinal fusion surgery in the united states: a study of the nationwide inpatient sample from 2001 to 2005 . $J$ Neurosurg Anesthesiol 2009;21:21-30.

16. Stamatakis $\mathrm{E}$, Zaninotto $\mathrm{P}$, Falaschetti $\mathrm{E}$, et al. Time trends in childhood and adolescent obesity in England from 1995 to 2007 and projections of prevalence to 2015. J Epidemiol Community Health 2010;64:167-74.

17. Michaleff ZA, Kamper SJ, Maher CG, et al. Low back pain in children and adolescents: a systematic review and meta-analysis evaluating the effectiveness of conservative interventions. Eur Spine J 2014;23:2046-58.

18. Savigny P, Kuntze S, Watson P, et al. Low Back Pain: early management of persistent non-specific low back pain. London: National Collaborating Centre for Primary Care and Royal College of General Practitioners.

19. Hayden JA, van Tulder MW, Malmivaara A, et al. Exercise therapy for treatment of non-specific low back pain. Cochrane Database Syst Rev 2005;(3):CD000335.

20. Keller A, Hayden J, Bombardier C, et al. Effect sizes of non-surgical treatments of non-specific low-back pain. Eur Spine $J$ 2007;16:1776-88.

21. Burns EM, Rigby E, Mamidanna R, et al. Systematic review of discharge coding accuracy. J Public Health (Oxf) 2012;34:138-48.

22. Campbell SE, Campbell MK, Grimshaw JM, et al. A systematic review of discharge coding accuracy. J Public Health Med 2001;23:205-11.

23. Sperrin M, Marshall AD, Higgins $V$, et al. Slowing down of adult body mass index trend increases in England: a latent class analysis of cross-sectional surveys (1992-2010). Int J Obes (Lond) 2014;38:818-24. 